University of Nebraska - Lincoln

DigitalCommons@University of Nebraska - Lincoln

Faculty Publications from the Harold W. Manter Laboratory of Parasitology

$12-1-1990$

\title{
Polymorphism of Eimerian Oocysts Can be a Problem in Naturally Infected Hosts: An Example from Subterranean Rodents in Bolivia
}

\author{
Scott Lyell Gardner \\ University of Nebraska - Lincoln, slg@unl.edu \\ Donald W. Duszynski \\ University of New Mexico, eimeria@unm.edu
}

Follow this and additional works at: https://digitalcommons.unl.edu/parasitologyfacpubs

Part of the Parasitology Commons

Gardner, Scott Lyell and Duszynski, Donald W., "Polymorphism of Eimerian Oocysts Can be a Problem in Naturally Infected Hosts: An Example from Subterranean Rodents in Bolivia" (1990). Faculty Publications from the Harold W. Manter Laboratory of Parasitology. 21.

https://digitalcommons.unl.edu/parasitologyfacpubs/21

This Article is brought to you for free and open access by the Parasitology, Harold W. Manter Laboratory of at DigitalCommons@University of Nebraska - Lincoln. It has been accepted for inclusion in Faculty Publications from the Harold W. Manter Laboratory of Parasitology by an authorized administrator of DigitalCommons@University of Nebraska - Lincoln. 


\title{
POLYMORPHISM OF EIMERIAN OOCYSTS CAN BE A PROBLEM IN NATURALLY INFECTED HOSTS: AN EXAMPLE FROM SUBTERRANEAN RODENTS IN BOLIVIA
}

\author{
Scott L. Gardner and Donald W. Duszynski \\ Department of Biology, The University of New Mexico, Albuquerque, New Mexico 87131
}

\begin{abstract}
Since 1986, 364 tuco-tucos (Ctenomys spp.) representing 7 species were collected from 16 major collecting areas representing at least 4 distinct ecological habitats in Bolivia, South America. All were examined for coccidia, and 125 (34\%) had oocysts in their feces including 84 of 236 (36\%) Ctenomys boliviensis from tropical palm/savanna habitats; 1 of $3(33 \%)$ Ctenomys conoveri from a chaco thorn forest; 3 of 7 (33\%) Ctenomys frater from medium altitude grass habitats; and 6 of 8 (75\%) Ctenomys lewisi and 31 of 35 (88\%) Ctenomys opimus from high altitude/puna habitats. None of 3 Ctenomys leucodon (high altitude/puna) or 72 Ctenomys steinbachi (tropical palm/savanna) were passing oocysts when examined. The 5 infected host species all had oocysts of Eimeria opimi Lambert, Gardner, and Duszynski, 1988, in their feces. These oocysts and their sporocysts varied greatly in size, both within and between host species, but qualitative characters (e.g., residua and wall texture) remained constant. Our conclusion, that all oocysts seen were $E$. opimi, was supported by multigroup discriminant analysis of 256 individual oocysts, 30-67 selected randomly from each Ctenomys sp. Minimum polygons enclosing the centroid (=multivariate mean) and the spread of individuals for each species group (OTU) showed significant overlap in discriminant space, and Geisser classification showed a $55 \%$ miss rate of individuals being classified into the wrong OTUs. Thus, oocyst and sporocyst lengths and widths cannot be used to separate morphotypes of $E$. opimi from different Ctenomys spp. from different geographic regions of Bolivia.
\end{abstract}

In the only other paper describing coccidian parasites from rodents of the family Ctenomyidae, Lambert et al. (1988) named 4 Eimeria spp. from Ctenomys opimus Wagner collected at 5 localities in western Bolivia. Since then, we have examined 6 additional Ctenomys spp., also from Bolivia, for coccidian oocysts and helminths. Four Ctenomys spp. had oocysts in their feces that varied greatly in size, as did their sporocysts, both within and between host species, but the qualitative features of all oocysts seen (sporozoite refractile bodies, oocyst outer wall, and residua) remained constant. Here we summarize our findings to support the conclusion that the coccidian seen in all host species was Eimeria opimi Lambert, Gardner, and Duszynski, 1988.

\section{MATERIALS AND METHODS}

Hosts were examined in the field soon after capture. All internal organs were examined for the presence of metazoan parasites and fecal pellets were removed from the lower bowel of each animal and preserved in vials containing $2 \%$ aqueous $(\mathrm{w} / \mathrm{v})$ potassium dichromate solution. Upon return from South America, samples were processed by filtering fecal suspensions through 40- and 60-mesh brass screens and incubating the filtrate at room temperature $(24 \mathrm{C})$ for 20 days and then examining them for oocysts (Duszynski et al., 1982). Oocysts were measured and photographed with a Zeiss Universal Photomicroscope equipped with both Neo-

Received 2 April 1990; revised 29 May 1990; accepted 11 June 1990. fluar and Nomarski-interference $100 \times$ objective lenses. All measurements are in $\mu \mathrm{m}$ with ranges of measurements in parentheses following the means.

Numerous sporulated oocysts were measured and photographed from each host species before it was obvious they were all qualitatively alike. Thus, it became necessary for us to determine whether or not these oocyst populations, or operational taxonomic units (OTUs), from geographically separate species of Ctenomys spp., could be separated into distinct morphotypes by discriminant analysis. To do this, we randomly selected 256 oocysts representing individuals from each Ctenomys spp. (including measurements on original data sheets of $E$. opimi oocysts from $C$. opimus in Lambert et al. [1988]), measured length and width of each oocyst and 1 sporocyst from each, and performed a multigroup discriminant analysis on all individuals of these 5 OTUs.

The statistical package BIOSTAT II (Pimentel and Smith, 1986) was used for all multivariate statistical procedures and Statistical Analysis Systems (SAS) was used to summarize univariate statistics. Levels of statistical significance were set prior to analysis at $P \leq$ 0.05 . To check for robustness of results, data were analyzed both with and without $\log _{10}$ transformation. Canonical variates analysis (=multigroup discriminant analysis) and associated Geisser classification were performed on 4 character-variables (length and width of oocysts and sporocysts) from all 256 sporulated oocysts. The initial hypothesis tested was Ho: using the 4 most commonly measured character variables of oocysts as a basis for separation of populations (OTUs), there is no mensural difference between these populations of Eimeria vs. Ha: differences between populations are evident.

For all comparisons of discrimination, Mahalanobis or generalized distances were used (Manly, 1986; Pimentel and Smith, 1986). 


\section{RESULTS}

Figure 1 shows the geographic distributions and the collection localities of the 7 Ctenomys spp. we examined for coccidia and Table I shows the number of animals examined, the habitat and department (state) in Bolivia in which they were collected, and the eimerians we found in each host group. Five of the host species were infected with $E$. opimi, which varied greatly in oocyst and sporocyst size both within and between host species (Table II, Figs. 2-11).

For multiple discriminant analysis, centroids of all groups were found to be significantly different with $98 \%$ of the variation in the data being accounted for by the first 2 canonical variates. Figure 12 shows a plot of discriminant scores that indicates the minimum polygons enclosing the spread of individuals for each OTU and the centroid or multivariate mean for each OTU. There is a great amount of overlap among all OTUs in discriminant space with the generally larger individuals from OTU OPIMUS occurring predominantly on the left side of the plot and the centroids of all OTUs occurring very close together. Geisser classification showed a $55 \%$ miss ( $45 \%$ hits) rate of individuals being classified into the wrong OTUs (Table III). This procedure calculates the generalized distances of individuals to the group centers (centroids) and allocates each individual to the group to which it is the closest (Manly, 1986). In the present analysis, the percentage of correct allocations of individual Eimeria is very low (Table III). This indicates that the 4 variables analyzed (oocyst and sporocyst lengths and widths) cannot be used to separate individual OTUs of this eimerian morphotype from different species of Ctenomys from different geographic regions of Bolivia. In addition, because the calculated distance units (=standard deviations) are very close in magnitude (Table IV), it is not possible to assign meaningful phenetic similarity values relating these OTUs.

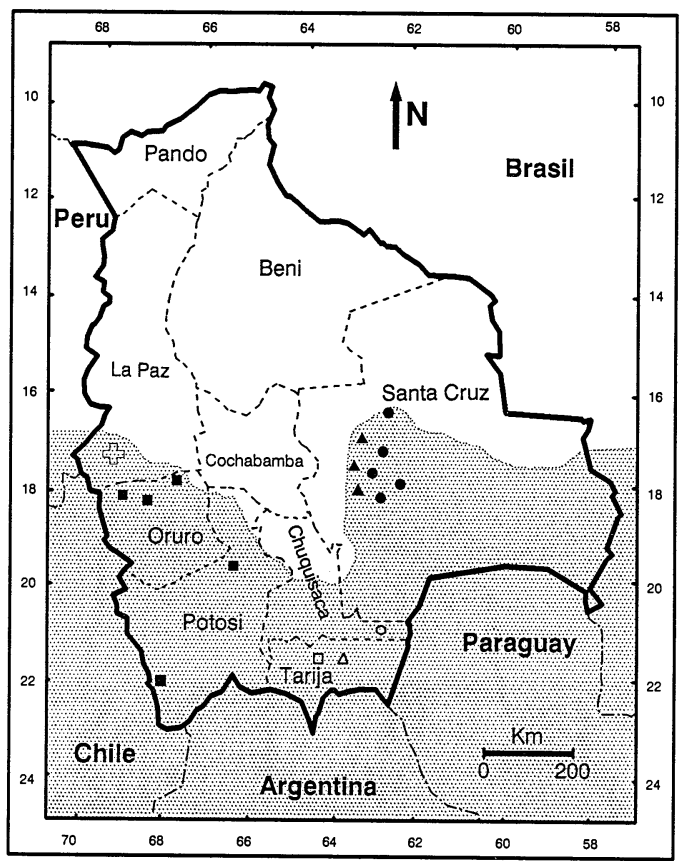

$$
\begin{array}{ll}
\bullet=\text { Ctenomys boliviensis } & \square=C . \text { lewisi } \\
0=\text { C. conoveri } & \square=C \text {. opimus } \\
\Delta=C . \text { frater } & \Delta=C . \text { steinbachi } \\
\uparrow=C . \text { leucodon } &
\end{array}
$$

FIGURE 1. Map of Bolivia and contiguous countries showing the major collecting localities of the 7 Ctenomys spp. included in this study. Shaded area represents the approximate distribution of Ctenomys spp.

\section{DISCUSSION}

The genus Ctenomys Blainville is highly specious with about 33 recognized species that occur in a wide variety of habitats from about $10^{\circ} \mathrm{S}$ latitude southward to the Strait of Magellan (Honacki et al., 1982). A previous paper (Lambert et al., 1988) reported 4 new Eimeria from C. opimus, a tuco that has one of the most extensive geographic distributions in Bolivia, relative to other Bolivian congeners (see fig. 1 in Lambert et al., 1988).

In this study we had the opportunity to ex-

FIGURES 2-11. Photomicrographs of pairs of polymorphic sporulated oocysts of Eimeria opimi collected from the feces of 5 Ctenomys spp. from Bolivia, South America. $\times 1,600.2,3$. From $C$. lewisi. 4, 5. From $C$. frater. 6, 7. From $C$. conoveri. 8, 9. From $C$. boliviensis. 10, 11. From C. opimus. Note that although the size of these oocysts varies, both within and between host species, that qualitative features are consistent including sculptured outer oocyst wall, polar body, granular and compact oocyst residuum, presence of a Stieda body, sporocyst residuum of a few large granules between sporozoites, and the large posterior refractile body of each sporozoite positioned at the top and bottom of each sporocyst. 


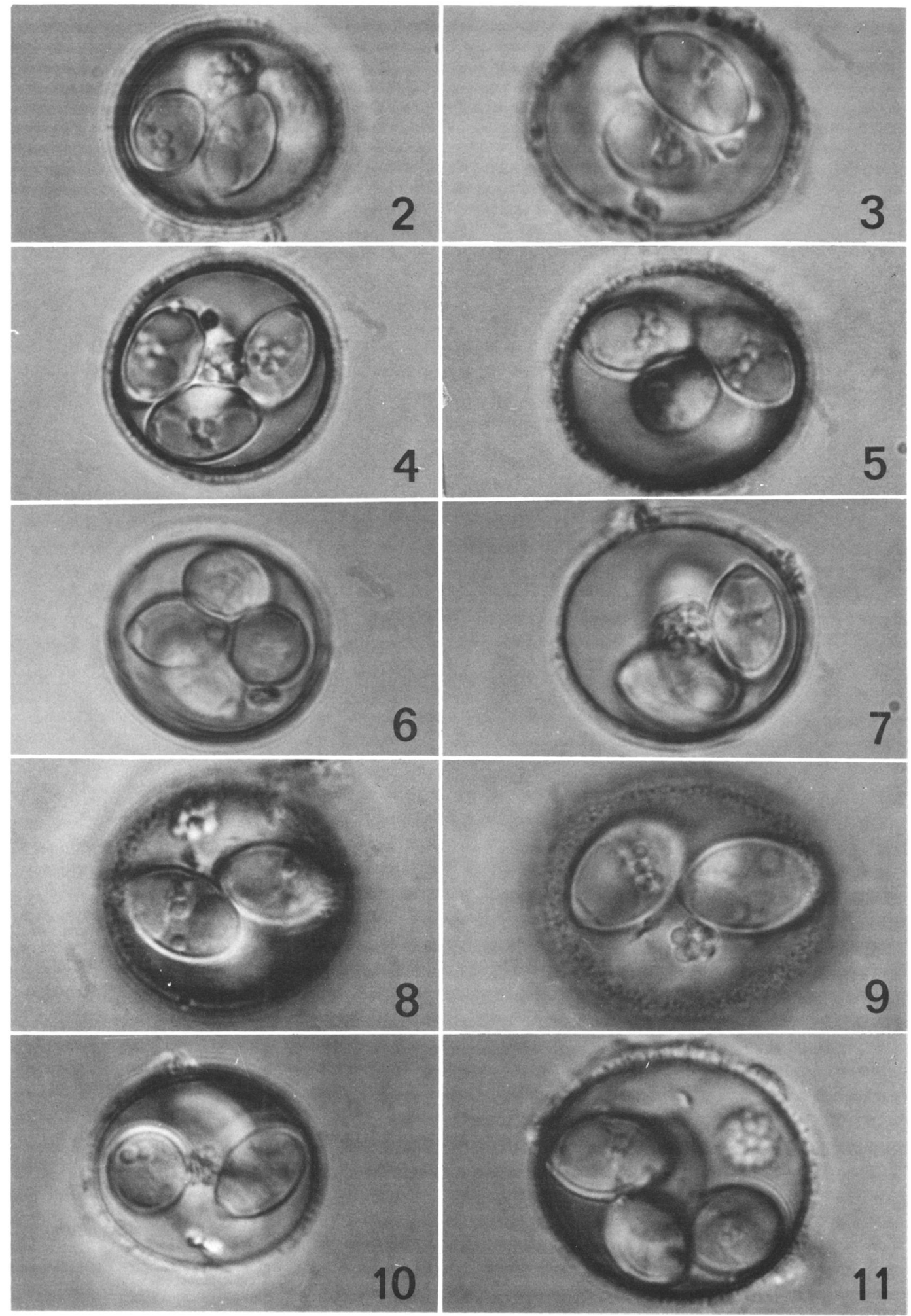


TABLE I. Eimeria opimi collected from 7 Ctenomys spp. taken from several habitat types in 6 departments, Bolivia, South America.

\begin{tabular}{|c|c|c|c|}
\hline Habitat/department & Rodent species & $\begin{array}{c}\text { Number infected/number } \\
\text { examined }(\%)\end{array}$ & Eimeria species \\
\hline \multicolumn{4}{|c|}{ High altitude/puna } \\
\hline $\mathrm{La} \mathrm{Paz}$ & C. leucodon & $0 / 3 \quad(0)$ & - \\
\hline Oruro & C. opimus* & $27 / 31 \quad(87)$ & $\begin{array}{l}\text { E. opimi, E. granifera } \\
\text { E. oruroensis, E. montuosi }\end{array}$ \\
\hline Potosi & C. opimus* & $4 / 4 \quad(100)$ & E. opimi, E. granifera \\
\hline Tarija & C. lewisi & $6 / 8 \quad(75)$ & E. opimi \\
\hline \multicolumn{4}{|c|}{ Medium altitude/grass } \\
\hline Tarija & C. frater & $3 / 7 \quad(33)$ & E. opimi \\
\hline \multicolumn{4}{|l|}{ Chaco thorn forest } \\
\hline Chuquisaca & C. conoveri & $1 / 3 \quad(33)$ & E. opimi \\
\hline \multicolumn{4}{|c|}{ Tropical palm/savanna } \\
\hline Santa Cruz & C. steinbachi & $0 / 72 \quad(0)$ & - \\
\hline Santa Cruz & C. boliviensis & $84 / 236(36)$ & E. opimi \\
\hline Totals & 7 & $125 / 364(34)$ & 4 \\
\hline
\end{tabular}

* These records from Lambert et al. (1988).

amine extensive collections of fecal material from 6 other Ctenomys spp. collected from a variety of localities and habitats throughout Bolivia (Fig. 1, Table I). Many samples from 4 of these other host species had sporulated oocysts that had a wide range of oocyst and sporocyst lengths and widths, but which had qualitative features that were uniform (e.g., spheroid oocyst residuum of large granules, finely sculptured outer oocyst wall, large sporozoite refractile body, Stieda body, dumbbell-shaped polar body, sporocyst residuum of 2-3 granules; see Figs. 2-11). In addition, the shape of the oocysts and sporocysts, as well as shape indices, remained constant (Table II).
Morphological variation between sporulated oocysts of individual eimerian species is known to occur (see review by Joyner, 1982), and, in some cases, oocysts of a single eimerian species are known to vary in size by as much as $40 \%$ during patency (Duszynski, 1971). Parker and Duszynski (1986) identified at least 4 problem areas that challenge those who try to identify oocysts from wild hosts and quantified and documented 1 of them, namely, phenotypic plasticity of oocysts, presumed to be a single parasite species, within the same or closely related host species. Here we document a natural situation in which oocysts presumed to be a single species

TABLE II. Mean oocyst and sporocyst lengths and widths $(\mu \mathrm{m})$, ranges (in parentheses), L/W ratios, and coefficient of variation (CV) of 5 OTUs of Eimeria opimi from 5 geographically separate species of Ctenomys from Bolivia, South America.

\begin{tabular}{|c|c|c|c|c|c|c|}
\hline \multirow[b]{2}{*}{ Ctenomys species } & \multicolumn{3}{|c|}{ Oocyst } & \multicolumn{3}{|c|}{ Sporocyst } \\
\hline & Length & Width & $\mathrm{L} / \mathrm{W}$ & Length & Width & $\mathrm{L} / \mathrm{W}$ \\
\hline C. boliviensis & 21.7 & 19.4 & 1.1 & 9.5 & 6.8 & 1.4 \\
\hline$(\mathrm{n}=61)^{*}$ & $(19-25)$ & $(15-22)$ & - & $(7-11)$ & $(6-8)$ & - \\
\hline $\mathrm{CV}$ & 6.9 & 8.1 & - & 8.9 & 9.5 & - \\
\hline C. conoveri & 20.9 & 19.2 & 1.1 & 10.3 & 7.0 & 1.3 \\
\hline$(n=43)$ & $(19-23)$ & $(17-21)$ & - & $(8-11)$ & $(5-8)$ & - \\
\hline $\mathrm{CV}$ & 6.0 & 4.1 & - & 8.8 & 9.4 & - \\
\hline C. frater & 21.7 & 19.9 & 1.1 & 10.5 & 7.0 & 1.5 \\
\hline$(\mathrm{n}=67)$ & $(19-26)$ & $(16-25)$ & - & $(9-13)$ & $(5-8)$ & - \\
\hline $\mathrm{CV}$ & 8.9 & 9.9 & - & 9.5 & 11.3 & - \\
\hline C. lewisi & 23.7 & 21.2 & 1.1 & 10.5 & 7.5 & 1.5 \\
\hline$(\mathrm{n}=30)$ & $(18-26)$ & $(17-25)$ & - & $(8-13)$ & $(5-8)$ & - \\
\hline $\mathrm{CV}$ & 8.8 & 9.8 & - & 13.4 & 13.8 & - \\
\hline C. opimus & 24.3 & 21.8 & 1.1 & 11.6 & 7.6 & 1.5 \\
\hline$(n=55)$ & $(18-29)$ & $(15-26)$ & - & $(10-13)$ & $(6-9)$ & - \\
\hline $\mathrm{CV}$ & 7.7 & 8.4 & - & 7.4 & 8.8 & - \\
\hline
\end{tabular}

${ }^{*} \mathrm{n}$, number of sporulated oocysts measured from each species. 
TABLE III. Results of Geisser classification on 5 OTUs of presumed Eimeria opimi from Ctenomys spp. in Bolivia. Read percentage of each row predicted into each column. Row titles represent actual OTU designations; column headings represent predicted OTU membership. For instance, no individual of OTU CONOVERI was classified into that OTU representing OPIMUS (row 1).

\begin{tabular}{lccccc}
\hline OTU name & CONOVERI & FRATER & LEWISI & OPIMUS & BOLI- \\
\hline VIENSIS \\
CONOVERI & 53 & 30 & 5 & 0 & 12 \\
FRATER & 31 & 25 & 13 & 16 & 13 \\
LEWISI & 0 & 7 & 33 & 40 & 0 \\
OPIMUS & 11 & 9 & 20 & 60 & 51 \\
BOLIVIENSIS & 21 & 13 & 13 & 2 & 51 \\
\hline
\end{tabular}

of Eimeria are found within closely related, but geographically separate, congeners.

The ctenomyids are among the most specialized burrowing rodents in South America and have arrived independently at the same life style and general morphologic characteristics as have their North American counterparts, the pocket gophers. Most species of Ctenomys are highly subterranean, exhibit low vagility, occur in relatively low population densities, and at least the 7 species we examined, occur in habitats that vary dramatically. Ctenomys opimus, Ctenomys leucodon, and Ctenomys lewisi all occupy high altitude regions in western Bolivia and were collected primarily in habitats (puna) on the Altiplano at altitudes greater than $4,000 \mathrm{~m}$. We should also note that only 3 individuals of $C$. leucodon were collected from only 1 locality in extreme west-central Bolivia and that the actual range of this species is, at present, unknown. Individuals of Ctenomys frater occur at more intermediate elevations, generally between 2,800 and 4,000 $\mathrm{m}$, and are found in a more montane/grassland habitat. The southeastern chaco, where individuals of Ctenomys conoveri were collected, is characterized by lowland dry thorn forest generally less than $600 \mathrm{~m}$ elevation. Specimens of Ctenomys steinbachi and Ctenomys boliviensis occur most commonly in the palm-nut/savanna region of east-central Bolivia, at about $250 \mathrm{~m}$. It seems of special interest that some tucos, C. leucodon and C. steinbachi, remain uninfected, whereas all other species, which do not share habitat and are distributed sparsely and rather isolated individually, seem to share a single coccidian species.

Also of interest is that the ctenomyids exhibit the highest known chromosomal variation for all mammals. Within Bolivia, for example, diploid $(2 \mathrm{~N})$ numbers range from 10 for $C$. steinbachi to 56 for $C$. lewisi and 1 species, C. boliviensis, has individuals that range in $2 \mathrm{~N}$ from 36 to 44 . The relative recency of origin, the wide geographic distribution, the great taxonomic diversity and the chromosomal variation within Ctenomyidae suggest that very active speciation is underway (Anderson et al., 1987; Cook et al., 1990). Although active speciation appears to be occurring, as evidenced by probable contact zones of different chromosomally variable populations of $C$. boliviensis, relatively less variation in morphological characteristics in oocysts from this species was noted compared with $C$. opimus (see group dispersions on the plots of discriminant scores, Fig. 12). To us, this indicates that E. opimi is conservative in its morphological characteristics and may represent a primitive species of parasite infecting the ctenomyid clade.

The concept of the evolutionary species (sensu Wiley, 1981) applies to OTUs of E. opimi, even though the OTUs are not distinguishable by either standard taxonomic methods or multiple

TABLE IV. Comparisons of generalized (Mahalanobis) distances between OTUs. Values also represent standard deviation units.

\begin{tabular}{|c|c|c|c|c|c|}
\hline OTU name & CONOVERI & FRATER & LEWISI & OPIMUS & $\begin{array}{l}\text { BOLI- } \\
\text { VIENSIS }\end{array}$ \\
\hline CONOVERI & 0.000 & - & - & - & - \\
\hline FRATER & 0.574 & 0.000 & - & - & - \\
\hline LEWISI & 1.705 & 1.327 & 0.000 & - & - \\
\hline OPIMUS & 1.946 & 1.482 & 1.215 & 0.000 & - \\
\hline BOLIVIENSIS & 1.336 & 1.247 & 1.237 & 2.197 & 0.000 \\
\hline
\end{tabular}




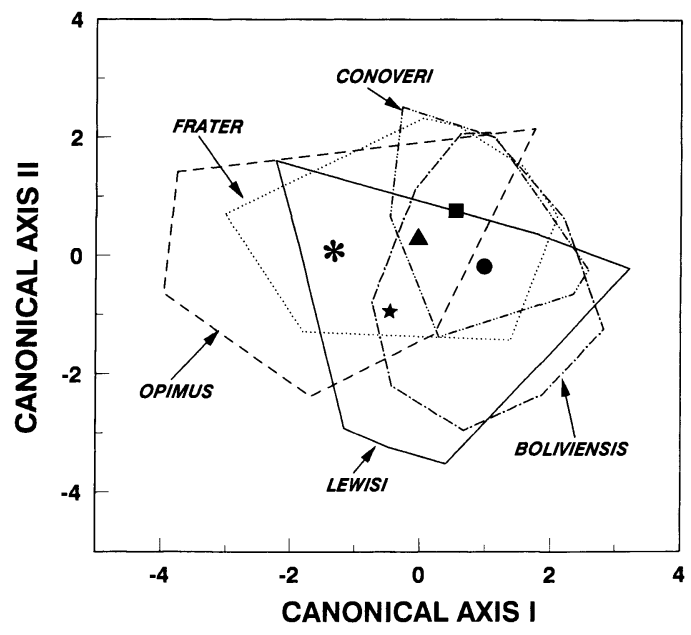

FIGURE 12. Plot of discriminant scores of mensural data for OTUs of Eimeria opimi from 5 species of Bolivian Ctenomys. Multivariate means (centroids) of Eimeria opimi are indicated on the plot as follows: $C$. conoveri, $\mathbf{\square}$; C. frater, $\mathbf{\Delta}$; C. lewisi, $\star$; C. opimus, *; and $C$. boliviensis,

discriminant analysis. It appears then that what we term E. opimi represents a primitive species complex (plesiomorphic parasite) that has had an ancient association with the ctenomyids. The genus Ctenomys is represented by a monophyletic group of relatively well defined species that are derived from an offshoot of the lineage comprising the octodontid rodents (Contreras et al., 1987; Gardner, 1988). In the case of E. opimi, these coccidians must either have invaded the ctenomyids early in the evolutionary history of Ctenomys (i.e., before the adaptive diversification of the group) or they were present in the lineage of octodontids that were precursors of the group now recognized as Ctenomyidae. If the former is true (Fig. 13A), then this species would not be expected to occur in octodontid rodents. If the latter is true (Fig. 13B), we would expect to find eimerians of the same morphotype, if not the same morphological species, in at least some species of octodontids.

Gardner (1988) found that nematodes of the genus Paraspidodera occur in a pattern similar to that outlined here for E. opimi among the same species of Ctenomys. The primary difference in this nematode-rodent system is that there has been a great amount of phyletic coevolution and associated morphological and biochemical diversification between the nematodes and their hosts relative to what we have documented for the Eimeria-Ctenomys system in Bolivia.

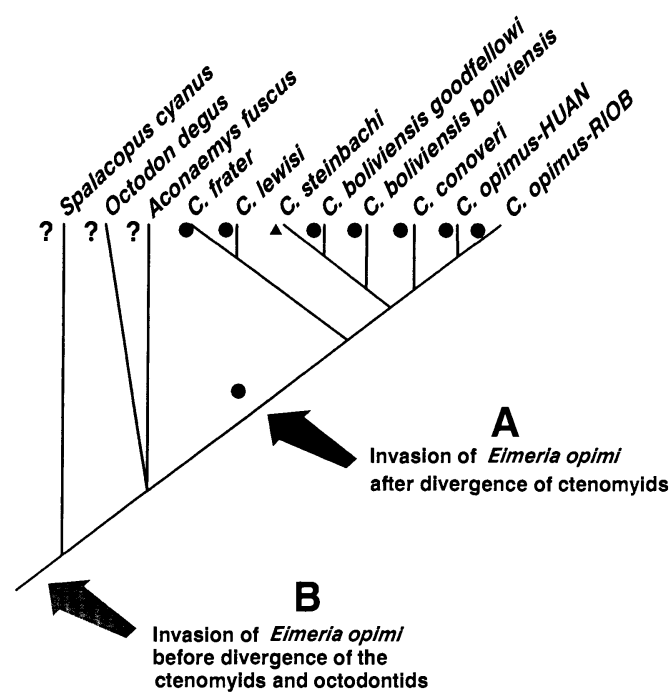

Figure 13. Cladogram of Ctenomys and octodontid outgroups (modified from Gardner, 1988) showing 2 possible invasion scenarios by Eimeria opimi into the basal ctenomyid lineage. Question marks indicate that these hosts have not yet been examined for the presence of coccidian parasites; - indicates that $E$. opimi occurs in that species, and $\boldsymbol{\Delta}$ indicates that no coccidian is reported from this host. Hypothetical invasion (A) shows these coccidians transferring only to the lineage giving rise to the rest of the extant species of Ctenomys. Scenario B shows a possible earlier occurrence of $E$. opimi in the primitive octodontid rodents that gave rise to the rest of the Ctenomyidae and Octodontidae.

\section{ACKNOWLEDGMENTS}

We sincerely thank many colleagues in biology at the University of New Mexico and the American Museum of Natural History for their help in collecting and/or processing the Ctenomys spp.: J. A. Cook, C. Shuster, N. Olds, J. S. Salazar, J. M. Goytia, Dr. T. L. Yates, Dr. S. Anderson, and, especially, Dr. O. C. J. Camacho. We also thank C. R. Lambert and M. J. Patrick for measuring and photographing the oocysts used in this study. This work was supported, in part, by NSF grants BSR-8408923 to T. L. Yates and BSR8612329 to S. L. Gardner, T. L. Yates, and D. W. Duszynski.

\section{LITERATURE CITED}

ANDerson, S., T. L. Yates, AND J. A. COOK. 1987. Notes on Bolivian mammals 4: The genus Ctenomys (Rodentia, Ctenomyidae) in the eastern lowlands. American Museum Novitates 2891: 1-20.

Contreras, L. C., J. C. TORRES-MURA, AND J. L. YÁÑEZ. 1987. Biogeography of octodontid rodents: An eco-evolutionary hypothesis. In Studies in neotropical mammalogy, essays in honor of Philip 
Hershkovitz, B. D. Patterson and R. M. Timm (eds.). Fieldiana Zoology, New Series 39: 401-411.

Cook, J. A., S. Anderson, And T. L. Yates. 1990. Notes on Bolivian mammals 7. The genus Ctenomys in the highlands. American Museum Novitates 2900: (in press).

DUSZYNSKI, D. W. 1971. Increase in size of Eimeria separata oocysts during patency. Journal of Parasitology 57: 948-952.

, G. EASTHAM, AND T. L. YATES. 1982. Eimeria from jumping mice (Zapus spp.): A new species and genetic and geographic features of $Z$. hudsonicus luteus. Journal of Parasitology 68: 1146-1148.

GARDNER, S. L. 1988. Phyletic coevolution between nematode parasites and their rodent hosts in Bolivia. Ph.D. Dissertation. University of New Mexico, Albuquerque, $166 \mathrm{p}$.

HonaCKI, J. H., K. E. KinMan, AND J. W. KoePPL (eds.). 1982. Mammal species of the world: A taxonomic and geographic reference. Allen Press, Inc., and the Association of Systematics Collections, Lawrence, Kansas, 694 p.
JOYNER, L. P. 1982. Host and site specificity. In The biology of the coccidia, P. L. Long (ed.). University Park Press, Baltimore, p. 35-62.

LAMBERT, C. R., S. L. GARDNER, AND D. W. DUSZYNSKI. 1988. Coccidia (Apicomplexa: Eimeriidae) from the subterranean rodent Ctenomys opimus Wagner (Ctenomyidae) from Bolivia, South America. Journal of Parasitology 74: 1018-1022.

MANLY, B. F. J. 1986. Multivariate statistical methods, a primer. Chapman and Hall, New York, $159 \mathrm{p}$.

PARKer, B. B., AND D. W. DuszYNSKI. 1986. Polymorphism of eimerian oocysts: A dilemma posed by working with some naturally infected hosts. Journal of Parasitology 72: 602-604.

Pimentel, R. A., AND J. D. Smith 1986. Biostat II. A multivariate statistical toolbox. Sigma Soft, Placentia, California, 212 p.

Wiley, E. O. 1981. Phylogenetics. The theory and practice of phylogenetic systematics. John Wiley and Sons, New York, 439 p. 